\title{
A HOMEOPATIA COMO PROPOSTA TERAPÊUTICA: EVIDÊNCIAS HISTÓRICAS E CIENTÍFICAS
}

\author{
HOMEOPATHY AS A THERAPEUTIC PROPOSAL: HISTORICAL AND SCIENTIFIC \\ EVIDENCE
}

\author{
Marize Alves Peixoto Macedo da Silva ${ }^{1}$ \\ Lívia Cabral Lobo ${ }^{2}$
}

\begin{abstract}
RESUMO: A homeopatia foi motivada, em 1796, por Christian Hahnemann e oferece os princípios da cura pelo semelhante, da experiência em pessoa sadia, o preceito da medicação única, diluída e dinamizada. No Brasil, a homeopatia foi trazida em 1840 , sendo admitida como uma especialidade médica no ano de 1980, e como uma especialidade farmacêutica em 1992. O fato de as medicações contarem com doses extremamente diluídas é uma das razões que tornam mais difícil a aceitação desta terapia pela comunidade. Todavia, a área científica tem recebido importantes evidências, principalmente como uma abordagem complementar, com base no vitalismo, em um modelo de atenção à saúde delineado de forma transdisciplinar, na busca pela integralidade do cuidado. Ao examinar tal situação, esse estudo ressalta o problema de pesquisa a seguir: é a homeopatia uma proposta terapêutica eficaz? O objetivo geral é identificar as principais características da homeopatia. No que se refere ao estabelecimento de objetivos específicos, evidenciam-se: verificar, sob a perspectiva histórica, a homeopatia desde sua proposta por Hahnemann até a visão contemporânea de Sankaram; investigar a utilização da homeopatia no Brasil, bem como sua inclusão no sistema de atenção à saúde; analisar as evidências científicas sobre a homeopatia no mundo e no Brasil. A Revisão Bibliográfica Narrativa, também conhecida por Revisão de Literatura, é o procedimento metodológico definido para esta pesquisa, com ênfase para a avaliação de questões sobre a adoção da homeopatia crescer, principalmente em função da percepção de suas virtudes como terapia sistêmica, com poucos efeitos adversos e pela questão do custo e do benefício, e parcialmente pela desconfiança na medicina convencional.
\end{abstract}

Palavras-chave: Especialidade Farmacêutica. Homeopatia. Proposta Terapêutica. Saúde. Terapia Sistêmica.

'Bacharelanda em farmácia pela Universidade Iguaçu (UNIG). Email: marizeapmacedodasilva@yahoo.com . Email: marizeapmacedodasilva@yahoo.com.

${ }^{2}$ Mestre em Ciências de Tecnologia de Processos Químicos e Bioquímicos pela Universidade Federal do Rio de Janeiro (UFRJ). Professora assistente no Departamento de Farmácia da Universidade Iguaçu (UNIG). Orientadora do trabalho.Email: livia.cl@hotmail.com. 
ABSTRACT: Homeopathy was motivated, in 1796, by Christian Hahnemann and offers the principles of healing by others, of experience in a healthy person, the precept of single, diluted and dynamized medication. In Brazil, homeopathy was introduced in 1840 , being admitted as a medical specialty in 1980 , and as a pharmaceutical specialty in 1992. The fact that medications have extremely diluted doses is one of the reasons that make its acceptance more difficult. therapy by the community. However, the scientific area has received important evidence, mainly as a complementary approach, based on vitalism, in a health care model outlined in a transdisciplinary way, in the search for comprehensive care. In examining this situation, this study highlights the following research problem: is homeopathy an effective therapeutic proposal? The general objective is to identify the main features of homeopathy. With regard to the establishment of specific objectives, the following are evident: to verify, from a historical perspective, homeopathy from its proposal by Hahnemann to Sankaram's contemporary vision; investigate the use of homeopathy in Brazil, as well as its inclusion in the health care system; analyze the scientific evidence on homeopathy in the world and in Brazil. The Narrative Literature Review, also known as Literature Review, is the methodological procedure defined for this research, with emphasis on the evaluation of questions about the adoption of homeopathy grow, mainly due to the perception of its virtues as a systemic therapy, with few effects adverse effects and the issue of cost and benefit, and partially due to distrust of conventional medicine.

Keywords: Health. Homeopathy. Pharmaceutical Specialty. Systemic Therapy. Therapeutic Proposal.

\section{INTRODUÇÃO}

Considerando as civilizações primevas, a arte da medicina era envolta por uma aura mística e religiosa, exercida por guias espirituais, sendo as doenças associadas a castigos merecidos. Com a intervenção de Hipócrates, na Grécia, a medicina passa a ter uma condição de ciência, com um corpo doutrinário, incluindo a história, o exame, a classificação e a predição das doenças junto das ações higiênico-dietéticas da prática terapêutica. Em função da influência de Hipócrates até o século XIX, admitia-se existir um princípio ou uma força vital, constituindo o chamado vitalismo, nessa visão encontravam-se Erasistrato, Galeno, Rhazes; Paracelso, Sydenham, van Helmont, Stahl, von Haller, Brown, Boerhaave, Mesmer, Virchow, Claude Bernard e tantos outros (TEIXEIRA, 1998).

No ano de 1796, o médico alemão Christian Frederich Samuel Hahnemann usa a visão vitalista como apoio ao seu método científico e experimental no tratamento de moléstias, chamado homeopatia (TEIXEIRA, 200o). Ainda no século XIX, os modelos mecanicista e cartesiano passam a ter maior importância, sobrevindo o modelo vitalista. A Medicina do 
século XX abandonou completamente a concepção vitalista aplicando-se às ciências exatas (TEIXEIRA, 2002).

A expressão homeopatia tem origem greco-latina e é oriunda de 'homeo' ou semelhante e de 'pathos' ou dor. É decorrente da medicina Hipocrática, já que seus preceitos são similares e ambas entendem o processo saúde-doença como provindo do equilíbrio do organismo. Outrossim, o sujeito é compreendido como um ser integrado e não como composto por porções isoladas (DINIZ, 2006).

Em território brasileiro, a homeopatia foi introduzida em 1840 pelo médico francês Benoit-Jules Mure, o qual era discípulo de Hahnemann, com o ensino da homeopatia sendo oficializado no ano de 1918 (DOLCE-FILHO, 2008). Apenas em I980 esta prática terapêutica foi reconhecida como uma especialidade médica, pelo Conselho Federal de Medicina, por meio da Resolução CFM I.00o/1980, fundamentada no preceito da similitude, experimentação em sujeitos sadios, medicação única, dinamizada e diluída (TEIXEIRA, 20II). O medicamento além de único, deve ser ajustado na dose e na classe de acordo com as necessidades do tratado, o que possibilita, para o tratamento de uma mesma doença, pacientes receberem medicações individualizadas (TEIXEIRA, 20I0; SANTOS; SÁ, 2014).

Um dos maiores obstáculos da homeopatia ser um tratamento de ampla utilização é a ausência de entendimento do mecanismo de ação das medicações, essas fazem uso de quantidades ultra diluídas. Para tanto, a compreensão dos princípios da homeopatia e das principais características do medicamento homeopático é crucial para que os profissionais possam fazer uso e contribuir para a manutenção da saúde da população (SANTOS; SÁ, 2014).

Embora exista uma série de obstáculos no contexto global em diversas áreas sociedade, economia, cultura, entre outras várias questões relevantes para a grande massa da populção mundial -, existem aproximadamente 500 milhões de indivíduos que fazem uso da homeopatia como terapia, o que equivale a $7 \%$ da população mundial (PUSTIGLIONE; GOLDENSTEIN; CHENCINSKI, 2017). Dentre as principais citações indicadas, destacam-se os autores a seguir: Teixeira (2014); Pustiglione, Goldenstein e Chencinski (2017) e Waisse (2017). Ao examinar tal situação, esse estudo ressalta o problema de pesquisa 
a seguir: é a homeopatia uma proposta terapêutica eficaz? O objetivo geral é identificar as principais características da homeopatia.

No que se refere ao estabelecimento de objetivos específicos, evidenciam-se: verificar, sob a perspectiva histórica, a homeopatia desde sua proposta por Hahnemann até a visão contemporânea de Sankaram; investigar a utilização da homeopatia no Brasil, bem como sua inclusão no sistema de atenção à saúde; analisar as evidências científicas sobre a homeopatia no mundo e no Brasil. A Revisão Bibliográfica Narrativa, também conhecida por Revisão de Literatura, é o procedimento metodológico definido para esta pesquisa, com ênfase para a avaliação de questões sobre a adoção da homeopatia crescer, principalmente em função da percepção de suas virtudes como terapia sistêmica, com poucos efeitos adversos e pela questão do custo e do benefício, e parcialmente pela desconfiança na medicina convencional.

A presente pesquisa foi estruturada da seguinte maneira: no primeiro capítulo, é realizada a introdução, com descrição sobre os objetivos gerais e específicos, justificativa, problema, metodologia e demais questões introdutórias ao presente estudo; no segundo capítulo, foi descrito um levantamento histórico da homeopatia; no terceiro capítulo, foi caracterizada a introdução da homeopatia no Brasil; no quarto capítulo, foram verificadas questões relevantes sobre a farmácia homeopática; no quinto capítulo, foram analisadas as evidências científicas da utilização desta terapia e sua inclusão no sistema de saúde; no sexto capítulo, é descrita a metodologia aplicada ao desenvolvimento da presente pesquisa; na última etapa, finalmente, são descritas as considerações finais, onde são abordadas as conclusões sobre o presente estudo.

\section{Levantamento Histórico da Homeopatia: Dos Autores Antigos aos Contemporâneos}

A homeopatia é uma especialidade médica que no decorrer de sua trajetória demonstrou resolutividade, custo reduzido, alto alcance e uma importante aceitação pela sociedade. A homeopatia oferece uma espécie de terapia sistêmica, segura e com uma excelente relação custo $\mathrm{x}$ benefício aos pacientes, caracterizando-se como uma opção médica sustentável (PUSTIGLIONE; GOLDENSTEIN; CHENCINSKI, 2017). 
Hahnemann é tido como o pai da homeopatia, apesar de não ter sido o descobridor, mas aplicando-a de maneira consistente. Em 1796, publicou o ensaio intitulado 'Ensaio sobre um novo princípio para se averiguar os poderes curativos das drogas, com alguns comentários sobre aquelas empregadas até o momento', no Jornal de Medicina Prática (TEIXEIRA, 2007).

No ano de I8ı́, Hahnemann publicou a primeira edição do 'Organon da arte de curar', neste foram estabelecidos os fundamentos metodológicos e filosóficos da homeopatia. Quando por volta de I832 uma epidemia de cólera assolou a Europa, Hahnemann prescreveu medicamentos homeopáticos e observou reduções nos índices de mortalidade. Ainda nesta época, escreveu a sexta e última edição do 'Organon', que só foi publicada em I92I (TEIXEIRA, 2009; TEIXEIRA, 2010).

Segundo a homeopatia, a razão das patologias encontra-se no desequilíbrio do princípio vital, sendo o tratamento homeopático a tentativa de reequilibrar tal distonia, retornando à saúde. Tal força vital seria instintiva e espontânea, mantendo o organismo equilibrado enquanto impera a saúde. A diferenciação entre o princípio vital e a força intelectual é clara desde o princípio das obras de Hahnemann (TEIXEIRA, 2002).

Um discípulo de Hahnemann, o médico Benoit-Jules Mure, veio ao Brasil em i840 e estabeleceu a Escola Homeopática do Rio de Janeiro, o Instituto Homeopático de Santa Catarina e a primeira farmácia homeopática (TEIXEIRA, 1999). Em função dos preceitos antropológicos, a homeopatia se fundamenta no modelo vitalista, onde os conceitos de 'princípio vital', 'mente', 'alma' e 'espírito' referem-se à condição humana imaterial, sendo usados na compreensão do processo saúde-doença, sendo imperativo para afastar erros de interpretação que poderiam resultar em um errôneo entendimento da abrangência do tratamento homeopático. A mente seria um órgão psíquico, que teria uma importância fundamental na inter-relação das essências imateriais que constituem o sujeito (TEIXEIRA, 2013).

Como a causa das patologias está na distonia da força vital, a terapia homeopática procura reequilibrar tal princípio. $\mathrm{Na}$ ausência de um real sentido para a força vital, se estabelecem diversas confusões doutrinárias. Na sequência, a elevação pela procura da 
homeopatia pelo mundo aumenta as necessidades de educação desta ciência (TEIXEIRA, 2014).

$\mathrm{Na}$ União Europeia, a homeopatia é parcialmente regrada, em seis dos 22 países integra-se ao sistema de saúde; em nove, os alunos de medicina entram em contato com a homeopatia em cursos introdutórios; e, em I8, o título de pós-graduado em homeopatia é oficialmente reconhecido. A Índia é líder na infraestrutura de educação e capacitação, aproximadamente 260 instituições de ensino ofertam cursos de graduação em homeopatia, junto de 70 pós-graduações nesse campo do saber (LMHI, 2014).

No final dos anos 1980, a chamada homeopatia contemporânea, entende o processo evolutivo das metodologias de repertórios e anamnese, seguida pela abordagem sistêmica, cerca de uma década depois, com nomes como Jan Scholten, Rajan Sankaran, Massimo Magialavori e Chaim Rosental, acrescentando o Sistema de Níveis, Miasmas e Reinos. A sexta edição do Organon e a criação do sistema cinquenta milesimal de dinamização, proposto por Hahnemann, prega que a cada 50.000 vezes de dinamização, se eleva o poder da terapia. A homeopatia sistêmica associa toda a homeopatia clássica e utiliza as fontes das medicações homeopáticas (DIAS, 200I).

As contemporâneas formas repertoriais de Sankaran (2013) e Scholten (2013) usam, afora as medicações policrestas e semipolicrestas, outras pouco utilizadas na clínica de repertorização tradicional, o que dificulta sua adoção por diversas vezes (DENEZ, 2015). A obra de Sankaran, 'A sensação em homeopatia' de 2010 defende a visão fundamentalista e inovadora citando o Organon. Em vários trechos, enfatiza que o homeopata deve ter conhecimento das obras básicas e do repertório da lei da semelhança e, assim escolher acertadamente a medicação. $\mathrm{O}$ autor adquire o status de inovador quando muda o núcleo da história do indivíduo tratado, de acordo com seu método, busca o distúrbio central básico, a sensação vital a partir da queixa principal. Sankaran entende a sensação como decorrente da ilusão que todo o paciente tem do seu próprio processo de doença (LABONIA FILHO, 20Io).

A ilusão defendida por Sankaran (2010) apoia-se em obras clássicas do hinduísmo, onde o mundo visível aos sentidos dos indivíduos não é verdadeiro ou real. Tal padrão ou sensação, de onde surge a ilusão, seria o equivalente à voz espiritual, da desarmonia entre as 
vozes em que se estabelece o conflito, e nesse sentido, os sintomas se originam deste distúrbio principal.

Diante dos conceitos indicados por Sankaran (2010), tais sintomas pertenceriam a diferentes níveis: o nome, sendo o diagnóstico da doença; o fato, ou a experiência de sua disfunção como um sintoma; o sentimento ou sua experimentação do transtorno será emocional; a ilusão, onde a vivência se dá da forma como a imaginação percebe o sintoma; a sensação, na qual o sujeito vive o sintoma em um grau geral; a energia, onde a experiência da queixa se dá como um padrão de energia e o sétimo e último nível, sem denominação, que liga o primeiro ao sexto nível (SANKARAN, 2010).

Para Sankaran (2010), a importância das mãos pode indicar o sintoma, de acordo com os gestos repetidos durante a anamnese, por meio de uma técnica que demanda conhecimento e uma longa consulta (LABONIA FILHO, 2010). No terceiro capítulo, serão caracterizados estudos epidemiológicos e elementos de risco em relação ao objeto do presente estudo.

\section{A Homeopatia no Brasil}

A homeopatia foi inserida no Brasil no ano de 1840 , por Benoît Jules Mure, suas convicções no campo social estavam de acordo com a homeopatia, já que incluía o tratamento de escravos e dos excluídos no Brasil Império. Com o avanço da República, a homeopatia recebeu entusiasmo institucional, com as figuras de Monteiro Lobato e Rui Barbosa (BRASIL, 2019).

A partir de 1930, a homeopatia perdeu um importante espaço no cenário nacional, cuja situação perdurou até a década de 1970, junto das ideias libertárias, de uma terapia alternativa até uma prática complementar, afiançada pelas políticas públicas. Apesar dos progressos da medicina moderna existe uma parte da população que não atinge um estado de saúde com as terapias clássicas ou convencionais, esta parte poderia ter vantagens com a homeopatia (TEIXEIRA, 2013).

Por vezes, a homeopatia é complementar à assistência de saúde tradicional, ou substitui esta, especialmente quando o paciente não tolera as demais terapias. É evidente um aumento das doenças crônicas em função da maior expectativa de vida, sendo os tratamentos 
ineficazes ou paliativos, além de custosos, assim como em outra proposta, pode não curar todas as patologias ou todos os afetados, mas a homeopatia oferta uma chance de cura para doenças agudas, crônicas, epidêmicas ou hereditárias (TEIXEIRA, 2014).

No Brasil, a homeopatia tem destaque no mundo, em função do alto grau de sua prática, e pela inserção em departamentos oficiais e acadêmicos. A partir da aprovação da Política Nacional de Práticas Integrativas e Complementares (PNPIC) pela Portaria $\mathrm{n}^{\circ}$ 971/2006, a homeopatia faz parte do Sistema Único de Saúde (SUS), que inclui práticas antes tidas como alternativas em um sistema abrangente (BRASIL, 2019).

\section{O Medicamento Homeopático}

Excluem-se da homeopatia, os florais, os medicamentos antroposóficos, a cromoterapia, a aromaterapia, a acupuntura, o reiki, a iridologia, o shiatsu, e outras práticas. As medicações homeopáticas estão enquadradas na categoria dos medicamentos isentos de prescrição (MIP), exceto os citados no Artigo 13 da Lei no 5.991/1973 (BRASIL, 2019)

As medicações homeopáticas derivam-se de substâncias de todos os reinos, isto é, animal, vegetal e mineral, de produtos gerados por organismos vivos, e sintetizados em laboratório. Tais substâncias devem ser trabalhadas de maneira criteriosa, de acordo com as regras dadas pela Farmacopeia Homeopática Brasileira (LASTA, 2010). O medicamento homeopático conceitua-se como a forma farmacêutica de dispensação fornecida de acordo com o preceito da semelhança, com propósito curativo ou preventivo, obtido pela metodologia da dinamização (FARMACOPEIA HOMEOPÁTICA BRASILEIRA, 2oII).

$\mathrm{Na}$ fabricação do medicamento homeopático, a escala determina a dose do insumo ativo e inerte em um dado medicamento (HOLANDINO, 2009). A farmacotécnica usa as escalas Decimal (X, D, DH), Centesimal (C, CH) e Cinquenta Milesimal ( $Q$, LH, ) de acordo com os métodos Hahnemanniano, Korsakoviano ou Fluxo Contínuo (SIQUEIRA, 2009). A escala centesimal foi criada por Hahnemann, sendo a mais usada no país, usando para cada parte de insumo ativo, noventa e nove partes de insumo inerte, e os veículos mais utilizados são a água purificada e o etanol (VANDERLEI, 2010).

Hahnemann estabeleceu três métodos, o dos Frascos Múltiplos, para formas farmacêuticas em escala decimal e centesimal; o de Trituração, usado para preparar na escala 
decimal e centesimal de drogas insolúveis e na escala cinquenta milesimal para as solúveis e insolúveis; e o Método Cinquenta Milesimal, para aquelas com potência elevada (SANTOS; SÁ, 2014). As escalas decimal, centesimal e dinamização são resultantes de diluições consecutivas de sucussões e/ou triturações de drogas, em insumos inertes, para desenvolver o poder da medicação (BRASIL, 2018).

A farmácia homeopática é regida por dispositivos legais, em 1851 ocorreu o mais antigo registro de uma farmácia homeopática, e até 1965 , quem dirigia a questão era a subcomissão de Assuntos Homeopáticos no Serviço Nacional de Fiscalização de Medicina e Farmácia. A partir do Decreto $n^{\circ} 57.477 / 1965$ e Portaria $n^{0}$ 17/1966, regulamentou-se a manipulação, o receituário, a industrialização e a comercialização de homeopáticos. Em 1976, aprovou-se a a primeira edição da Farmacopeia Homeopática Brasileira, esta publicação encontra-se na terceira edição (20II) e orienta a produção de medicamentos e a regulamentação das áreas farmacêuticas envolvidas no controle de fármacos e insumos (BRASIL, 20II; BRASIL, 2019).

Em 2014, a Lei ${ }^{\circ}$ I3.02I sancionou a transformação da farmácia em um estabelecimento de saúde, regendo as ações e serviços de assistência, ajudando o Estado a implementar políticas de prevenção e recuperação da saúde (BRASIL, 2019). Sendo de responsabilidade do farmacêutico homeopata a fundamentação e implantação dessas ações (BRASIL, 2014).

$\mathrm{Na}$ manipulação de uma homeopatia é fundamental cumprir o estabelecido nas normatizações vigentes, tais como a Resolução do CFF n ${ }^{\circ}$ 576/2013, que reescreveu o Artigo Io da Resolução CFF n 440/2005, que trata do exercício da responsabilidade técnica em homeopatia:

Art. $\mathrm{I}^{\circ}$ - Considerar habilitado para exercer a responsabilidade técnica de farmácia ou laboratório industrial homeopático que manipule ou industrialize os medicamentos e insumos homeopáticos, respectivamente, o farmacêutico que comprovar uma das seguintes qualificações:

a) ter cursado a disciplina de homeopatia com conteúdo mínimo de 6o (sessenta) horas no curso de graduação, além de estágio obriga- tório com o mínimo de 120 (cento e vinte) horas nas farmácias de Instituições de Ensino Superior ou conveniadas, em laboratórios de medicamentos e/ou de insumos homeopáticos;

b) possuir título de especialista ou curso de aprimoramento profissional em homeopatia que atenda as resoluções vigentes do Conselho Federal de Farmácia (BRASIL, 2019, p. 29).

Além disso, o farmacêutico deve cumprir as Boas Práticas de Manipulação, segundo a RDC Anvisa $n^{\circ} 67 / 2007$ e a RDC Anvisa $n^{\circ}$ 87/2008 (BRASIL, 2007; BRASIL, 2008; 
BRASIL, 2019). O farmacêutico homeopata ter um conhecimento profundo da filosofia e da medicina homeopática, no país as mais importantes escolas homeopáticas são a Unicista, que prescreve somente um medicamento, com base nos sintomas; a Alternista ou pluralista, com a adoção de dois ou mais medicamentos alternados; a Organicista com a prescrição do medicamento orientada aos órgãos afetados, de acordo com as queixas; e a Complexista onde são prescritas suas ou mais medicações simultâneas (BRASIL, 2019).

Vários especialistas em homeopatia tentam explicar o mecanismo de ação das drogas adotadas, LIMA et al. (2012) traz publicações que tratam da droga ultra diluída em um veículo, como uma molécula de memória, capaz de provocar modificações corporais. Tal molécula seria potencializada por meio da dinamização, em função da ruptura de algumas das suas partículas atômicas liberando sua energia ativa.

Também há uma corrente que defende que uma diluição infinitesimal é capaz de perdurar o poder de acionar um receptor celular da mesma forma que a substância original de onde derivou, em virtude de o soluto gerar nanoestruturas no solvente, tais nanoestrututas seriam responsáveis pela associação entre o soluto e o receptor. Uma outra explicação reside no fato de as medicações homeopáticas atuarem por meio da regulação da expressão gênica, as substâncias seriam reconhecidas pelos receptores celulares e desencadeariam modificações em genes para a cura da doença. A administração segue a lei dos semelhantes, que objetiva acionar uma reação orgânica vital com vistas à cura (FONTES et al., 2012).

Administrados isoladamente ou em complexo, os medicamentos são escolhidos pelos sintomas ditados pelo paciente pela patogenesia, encontrada em um compêndio homeopático chamado de matéria médica (MAGALHÃES; NARDINI; NAKAMURA, 2018). A segurança no uso da homeopatia ainda é pouco menos tratada do que sua eficiência, pela pouca chance de efeitos adversos serem derivados de substâncias tão diluídas ou por não haver consenso sobre os efeitos dos medicamentos. Algumas revisões sistemáticas de medicamentos homeopáticos sugerem que esses produzem mais efeitos colaterais quando comparados aos placebos, apesar de leves e transitórios (DANTAS, 2017). 


\section{Evidências Científicas da Homeopatia e a Sua Importância Como Método Terapêutico}

A homeopatia é usada no tratamento de patologias agudas ou crônicas, dores de cabeça, infecções, problemas digestórios, tumores e dificuldades psicológicas (SINSEN, 2010). A terapia homeopática foi corroborada em patologias cardíacas e respiratórias, onde as doses eram tão reduzidas que não era possível distingui-las do placebo, mas era observada uma melhora nos sintomas dos tratados em relação aos que receberam placebo (LIMA et al., 2012).

Um elegante levantamento de publicações produzidas na Europa, EUA, Índia e Brasil, o Scientific Framework of Homeopathy: Evidence Based Homeopathy retrata o perfil dos que utilizam a homeopatia como tratamento. Pessoas com alto grau de escolaridade, entre 33 e 55 anos, com vida saudável e atitude positiva em relação à terapêutica, ou seja, capazes de ter uma opção informada. Na Europa se sobressaem alguns fatores determinantes dessa escolha, tais como a preocupação com os efeitos adversos em outros métodos; a falta de resultado das terapias convencionais; as experiências positivas em consultas; a preferência pessoal; o menor custo; o bem-estar geral; a crença no conceito holístico; a conscientização sobre o uso dos antibióticos; e a desconfiança na medicina convencional (PUSTIGLIONE; GOLDENSTEIN; CHENCINSKI, 2017).

Lima et al. (2012) abordaram a fertilidade humana, cujas afecções são cada vez mais frequentes, porém a terapia de reposição hormonal eleva a incidência de câncer mamário e endometrial, enquanto a homeopatia trata o sujeito como um todo. Vários autores citam que a parte física e psicológica deve ser tratada, medicações como o Caulophyllum e a Cimicifuga regulam as contrações uterinas. A avalição dos efeitos da terapia homeopática em seres humanos é realizada pelo uso em voluntários sadios e em doentes, uma primeira revisão sistemática foi publicada por Dantas e Rampes (2000).

Diversos ensaios clínicos controlados consideraram a incidência de efeitos colaterais mais frequentes naqueles que fizeram uso de medicamentos homeopáticos quando comparados aos com placebo (DANTAS, 2017). Uma revisão da literatura demonstrou que estudos multicêntricos recentes observaram que ultra diluições de histamina podem inibir a degranulação dos basófilos fomentada por anticorpos anti-IgE, diversos estudos também foram conduzidos em culturas de células, vegetais e animais, comprovando que substâncias 
dinamizadas mostram efeito primário similar à substância em forma bruta (TEIXEIRA, 20II).

Em relação aos sintomas característicos, Hahnemann (1995) hierarquiza as alterações mentais e psíquicas como questões importantes para a escolha da substância, em função de ser necessário observar em cada caso individual, o sintoma das perturbações mentais e psíquicas, pela escolha de medicamentos que sejam capazes de produzir um estado psíquico ou mental semelhante. $\mathrm{O}$ autor é contrário à utilização de mais de um medicamento simultaneamente, baseado na experimentação patogenética realizada com medicamentos simples e únicos:

Em nenhum caso de tratamento é necessário e, por conseguinte, não é admissível administrar a um doente mais do que uma única e simples substância medicamentosa de cada vez. É inconcebível que possa existir a menor dúvida acerca do que está mais de acordo com a natureza e é mais racional: prescrever uma única substância medicamentosa simples e bem conhecida num caso de doença ou misturar várias diferentes. $\mathrm{Na}$ única, verdadeira, simples e natural arte de curar, a homeopatia, não é absolutamente permitido dar ao doente duas substâncias medicamentosas diferentes de uma só vez. (HAHNEMANN, i995, p. 273).

Isto posto, o tratamento acertado deve considerar a individualização da substância única de acordo com os sintomas mais característicos, possibilitando que uma mesma doença seja tratada por medicações únicas distintas em momentos diferentes (TEIXEIRA, 20II).

Dantas (2017) traz uma revisão de ensaios patogenéticos homeopáticos conduzidos no Reino Unido, com distintos medicamentos em diluições de $3 \mathrm{D}$ a $200 \mathrm{C}$. A incidência de efeitos patogenéticos foi de $54,3 \%$, e a incidência de sintomas por voluntário foi de 18,8 . Cerca de 19 artigos relataram casos ou séries de casos de efeitos adversos, com agravamentos de sintomas já estabelecidos após a administração, como pelo uso de Pulsatilla, Baryta carbonica, Sulphur, Calcarea carbonica, Sepia, Belladonna, Ipeca, Phosphorus ou Borax. Uma outra revisão sistemática indicou que os efeitos adversos variam de leves a severos, com óbitos e intoxicações, porém foram incluídas tinturas de vegetais venenosos ou substâncias tóxicas sem diluição. Um outro estudo brasileiro relatou alopecia em pacientes depois de mesoterapia homeopática, onde se injetou no couro cabeludo do paciente Lilium compositum, Solanum compositum, Thuja e Tanacetum, produtos não homeopáticos. Uma recente revisão foi publicada em 2016, contendo 28 estudos de grande qualidade metodológica segundo os 
parâmetros estabelecidos pela Cochrane Collaboration, estes relataram efeitos leves $(68 \%)$ e moderados $(25 \%)$.

Por ser uma prática terapêutica individualizada é de esperar dificuldades de delineamento em ensaios clínicos. Uma metanálise publicada no British Medical Journal, analisou a qualidade metodológica de 107 trabalhos placebo-controlados, sugerindo que somente 22 deles teriam qualidade satisfatória, entre eles, is teriam mostrado eficácia da terapia homeopática sobre o uso do placebo. Em função de tais resultados, parece existir evidências positivas, porém insuficientes para conclusões definitivas (TEIXEIRA, 20II).

A eficiência e a segurança da homeopatia em crianças apresentando amigdalite recorrente, um processo inflamatório infeccioso nas tonsilas palatinas, foi avaliada em um estudo prospectivo, duplo-cego, randomizado, onde foram estudadas 40 crianças entre três e sete anos de idade por quatro meses; vinte foram tratadas com Baryta carbônica, indicada por inúmeros autores. O tratamento foi eficaz quando comparado ao placebo, excluindo $78 \%$ das crianças da indicação cirúrgica, sem ter provocado eventos adversos (FURUTA et al., 2017).

Uma revisão sistemática acerca da efetividade da homeopatia foi conduzida por Waisse (2017), utilizando o relatório da Liga Médica Homeopática Internacional (LMHI) de 2014, citando-se sete revisões com metanálise, seis delas indicaram que os efeitos da homeopatia não seriam compatíveis ao placebo, I9 outros estudos publicados recentemente mostram que $84,20 \%$ exibiram ao menos um desfecho positivo. Assim, efeitos específicos parecem ser possíveis e esperados, inclusive alguns autores sugerem bases para a discussão de benefícios para pacientes com fibromialgia e rinite alérgica. À medida que o mecanismo da ação das drogas homeopáticas se torna mais plausível, as incertezas quanto à eficiência e efetividade clínica deverão ser sanadas (WAISSE, 2017).

Estomatites virais encaixam-se na classificação hahnemanniana de doenças dinâmicas naturais agudas coletivas epidêmicas, causada pelo vírus Herpes simples ou Coxsackie, um trabalho estudou a totalidade de sintomas, classificou e agrupou-os (gênio epidêmico) por meio das ferramentas de repertorização homeopática e o Repertório de Homeopatia Pediátrica para buscar medicamentos, sendo Borax (BOR), Arsenicum álbum (ARS), Mercurius solubilis (MERC) e Sulphuricum acidum (SUL-AC) os mais experimentados (GRECK, 20I6). O gênio epidêmico permite observar por semelhança entre as diversas 
substâncias, aquela mais acertada ao quadro da epidemia. O objetivo de tal prática é otimizar o tempo de consulta, de repertorizações individuais e de intervenções nas epidemias (GRECK, 2016).

Entre os preceitos da homeopatia, a utilização de medicações dinamizadas, potencializadas ou ultra diluídas, em concentrações menores que I molécula-grama da substância, relativo à constante de Avogadro (6,02 x 10 $\left.^{-23}\right)$, estimula as grandes críticas à terapia homeopática, em função do sistema dose-dependente da farmacologia contemporânea. Um trabalho avaliou ${ }_{1} 67$ estudos experimentais, onde 48 deles alcançaram os parâmetros mínimos de qualidade metodológica e 29 observaram efeitos em plantas. Embora existam falhas metodológicas em estudos publicados anteriormente, a pesquisa homeopática em plantas como modelo experimental e pelo avanço da agroecologia, é promissor ao mecanismo de ação e sua aplicação terapêutica (TEIXEIRA; CARNEIRO, 2017).

\section{I A Inclusão da Homeopatia na Sociedade e nos Sistemas de Atenção à Saúde e Ensino no Brasil}

A literatura é unânime em indicar a figura de Mure como o fundador da homeopatia no país, esta foi reconhecida como uma prática médica desde o término do século XIX, tendo sido citada no Decreto Imperial nº 9.554 de i886. Nesse período, médicos se organizavam na Sociedade de Medicina e Cirurgia, originada em 1829 , e os médicos homeopatas (PUSTIGLIONE; GOLDENSTEIN; CHENCINSKI, 2017).

Alguns episódios foram marcantes na trajetória da homeopatia como especialidade médica e curativa, em 1985 se deu a celebração de uma parceria entre o Instituto Nacional de Assistência Médica da Previdência Social, a Fiocruz, a Universidade Estadual do Rio de Janeiro e o Instituto Hahnemaniano do Brasil, a fim de institucionalizar a assistência homeopática na rede pública. A 8ª Conferência Nacional de Saúde (CNS) em 1986 marcou a oferta da PNPIC no sistema de saúde nacional. Em 1995, instituiu-se o Grupo Assessor Técnico-Científico em Medicinas Não Convencionais, mediante a Portaria GM no 2.543 e em 1999 incluiu-se as consultas médicas em homeopatia e acupuntura entre as opções do SIA/SUS (BRASIL, 2018). 
O Decreto n ${ }^{\circ}$ 78.841/1976 aprovou a Farmacopeia Homeopática Brasileira e, em 1980, a Resolução no r.ooo do Conselho Federal de Medicina instituiu a homeopatia como especialidade médica, a ser desempenhada por médicos adequadamente capacitados, esta resolução foi ratificada pela Resolução no $1.295 / 1989$ e n⿳o $1.634 / 2002$, modificada pela no I.659/2003, com uma nova redação pela no 1.763/2005, no 1.785/2006 e no 1.970/201I (PUSTIGLIONE; GOLDENSTEIN; CHENCINSKI, 2017).

De acordo com a Resolução ı.00o/1980 do CFM, a concessão do título de homeopata se dava pela formação de dois anos, cursada em instituições de pós-graduação em homeopatia, desde que participantes do Conselho de Entidades Formadoras (CEF) da Associação Médica Homeopática Brasileira (AMHB), fiscalizados pela Comissão Científica e de Avaliação de Cursos da AMHB. Após a conclusão do curso, o candidato poderá realizar uma prova a fim de obter o diploma, segundo a Faculdade de Medicina da Universidade de São Paulo e os Conselhos Regional e Federal de Medicina, a homeopatia figurava na $26^{-}$posição de especialidade médica, entre as 53 possíveis, já em 2013 cerca de 2.458 profissionais estavam registrados, figurando na terceira posição como a segunda especialidade de profissionais da pediatria (PUSTIGLIONE; GOLDENSTEIN; CHENCINSKI, 2017). A homeopatia é ofertada em, no mínimo, dez universidades públicas, além de inúmeras atividades de ensino e pesquisa (BRASIL, 2018).

\subsection{Política Nacional de Práticas Integrativas e Complementares (PNPIC)}

A Política Nacional de Práticas Integrativas e Complementares (PNPIC) tem como meta a ampliação do acesso da população em geral aos produtos e serviços ligados a Práticas Integrativas e Complementares em Redes de Atenção à Saúde (RAS), de maneira eficiente, segura e com cunho multiprofissional, conforme as diretrizes do SUS. Afora a homeopatia, essa política integra as plantas medicinais e fitoterapia, a medicina tradicional chinesa, a acupuntura, a medicina antroposófica e o termalismo social (BRASIL, 2018).

A contar dos anos 1980, diversos estados e municípios passaram a ofertar a assistência homeopática como uma especialidade médica aos pacientes que procuravam o serviço, embora ainda de forma isolada e descontinuada, por não existir uma política pública. No ano de 1988, por meio da Resolução nº 4, a Ciplan estabeleceu regras ao atendimento em 
Homeopatia em serviços de saúde e, em I999, o Ministério da Saúde introduziu a consulta médica (BRASIL, 2018).

A partir da criação do SUS ampliou-se a oferta do atendimento homeopático, esse fato pode ser verificado pelo aumento na quantidade de consultas desde a inserção do procedimento, com um acréscimo anual de 10\%. Em 2003, a homeopatia estava presente em 20 unidades da federação, 16 capitais, 158 municípios, com a atuação de 457 profissionais médicos (BRASIL, 2006). Apesar de maior oferta de serviços, a assistência farmacêutica homeopática não cresce na mesma proporção, segundo a $\mathrm{AMHB}$, em 2000, somente $30 \%$ dos serviços da rede SUS ofereciam medicação homeopática. Informações do Ministério da Saúde de 2004 demonstraram que somente 9,6\% dos municípios possuíam farmácia pública de manipulação. No gráfico I pode ser visualizada a condição mais atual (BRASIL, 20I8).

Segundo as premissas estabelecidas na PNPIC, o desenvolvimento da homeopatia tem cunho multiprofissional em consonância com o nível de atenção, incorporando-se em variados graus de complexidade do sistema, dando ênfase à atenção básica, pela prevenção de doenças e recuperação da saúde, por meio de possibilitar condições à boa prática em homeopatia, infraestrutura e insumos. $\mathrm{O}$ apoio e o fortalecimento de iniciativas na atenção homeopática básica obedecem aos critérios estabelecidos na legislação vigente - Figura I (BRASIL, 2018).

Figura I - Distribuição das práticas integrativas e complementares no Brasil.

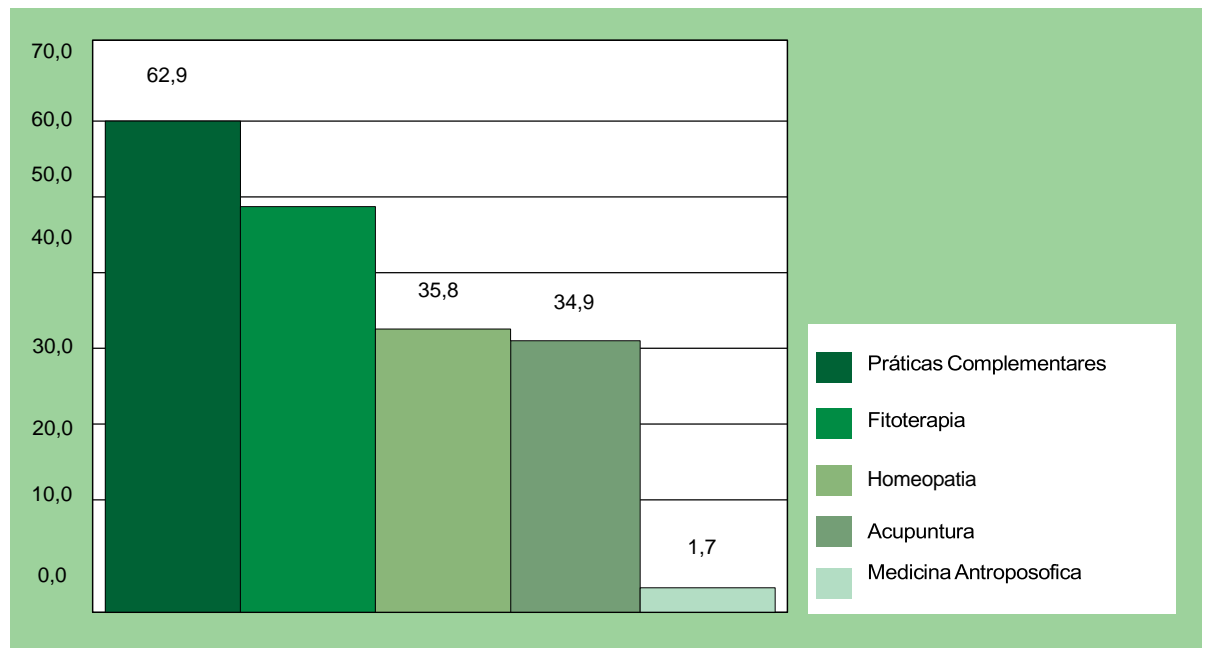

Fonte: Brasil (2018) 
Em Santa Catarina, foi realizado um levantamento sobre os medicamentos homeopáticos de farmácias, os resultados obtidos indicam que os medicamentos policrestos são os mais frequentemente prescritos tanto no SUS quanto na rede privada. $\mathrm{Na}$ avaliação específica do SUS, existe uma maior procura por formulações complexas, cujos pacientes sentem-se acolhidos em um tratamento integral, além de considerarem o medicamento eficiente (DENEZ, 2015).

Sob o ínterim da educação permanente em saúde, uma pesquisa foi desenvolvida a fim de avaliar as possibilidades que a construção de histórias de vida oferece nos encontros de projetos terapêuticos compartilhados. Concluiu-se que as histórias de vida intensificam a operação coletiva e o projeto terapêutico compartilhado, além de permitirem a ampliação da integração das equipes e o usuário operando como poderosos dispositivos ao cuidado em saúde (SLOMP JUNIOR; FEUERWERKER; MERHY, 2015).

\section{Metodologia}

No desenvolvimento desse estudo, utilizou-se a metodologia da Revisão da literatura, essa metodologia é baseada, conforme Marconi e Lakatos (2017), no levantamento de textos publicados, em livros, periódicos, textos avulsos e impressos. A pesquisa qualitativa é composta por um conjunto de conceituações e hipóteses, as quais provém de inúmeras áreas do saber, situando o observador/pesquisador no espaço de seu objeto de pesquisa (DENZIN; LINCOLN, 2000). Em tal panorama, as representações geradas fundamentam-se na perspectiva interpretativa dos eventos. Sua heterogeneidade deriva de não se restringir a uma estratégia específica e singular, seja quanto ao método, seja quanto à interpretação (MINAYO, 2014). Minayo (2014) ainda salienta que as metodologias são variáveis, adotando procedimentos e abordagens derivadas de áreas diversas como a etnometodologia, fenomenologia, hermenêutica, observação participativa, dentre outras. Isto posto, ao apreciar-se e visualizar pesquisas qualitativas de relevância, pode-se conduzir pesquisas de revisão bibliográfica, e também revisões associadas a pesquisas qualitativas.

A revisão da literatura do tipo narrativa é conforme Melnik e Fineout-Overholt (2018), uma pesquisa que abrange inúmeras publicações, não seria mandatório abordar sistematicamente a dinâmica da metodologia adotada para a procura, seleção e análise dos 
textos encontrados, diferentemente das demais técnicas de revisão bibliográfica. Gil (2017) defende que o pesquisador possa trabalhar com uma série de fenômenos muito mais amplos, ou seja, a opção de um método de revisão permite uma visão mais ampla do objeto de estudo.

Entre as vantagens da metodologia de revisão narrativa podem ser citadas a pergunta de pesquisa passível de ser respondida, a revisão melhorar de modo significativo as revisões já disponíveis sobre o tema, a não delimitação do estudo pelo tempo de revisão, identificação dos critérios para incluir e excluir o texto ao estudo, exclusão de estudos repetidos, relatar a heterogeneidade encontrada, reconhecer e assinalar os possíveis vieses de estudo, conceber afirmativas e conclusões adstritas ao fatos da revisão, sem extrapolações indevidas (SOUSA; FIRMINO; MARQUES-VIEIRA; SEVERINO; PESTANA, 2018).

A revisão do tipo narrativa assume um cunho descritivo e bibliográfico, propondo-se a avaliar e descrever um objeto exclusivo, considerando os principais estudos publicados por outros pesquisadores, com o intuito de descrever sobre esse e demais temas atinentes ao primeiro. Para Gil (2017), a revisão inclui a etapa exploratória, onde o pesquisador se debruça sobre o objeto a ser pesquisado, seus preceitos, premissas, teorias atinentes, metodologias mais indicadas e temas operacionais, basicamente focado em construir seu projeto investigativo; quanto à fase de operacionalização da pesquisa, podem ser classificadas três outras fases, a investigação nas bases de dados sobre o assunto; a seleção dos textos encontrados e a colheita dos dados, propriamente dita.

Moreira (2004) destaca que qualquer revisão bibliográfica deve ser acessível, sendo indispensável a escolha adequada das bases de dados no âmbito de colheita de dados, o planejamento e o desenvolvimento do estudo deve seguir uma série delineada de perguntas ou objetivos preestabelecidos, incluindo a escolha do tema, a definição do objetivo geral, dos objetivos específicos, a utilidade do estudo na área escolhida, a investigação da bibliografia, a primeira leitura ou com propósito de inspecionar os textos buscados, identificar os trabalhos mais adequados a responder as perguntas, priorizar a leitura dos textos selecionados, avaliar criticamente e comparar possíveis pontos concordantes e discordantes entre os autores mais citados. Assim, é de fundamental importância o delineamento dos procedimentos de análise, considerando a temática de pesquisa, as bases de dados e o período de localização espacial das publicações (BORNMANN; MUTZ, 2015). 
É comum que a revisão narrativa aborde uma ou mais questões de pesquisa, em certas situações tal tipificação de revisão bibliográfica seria imprescindível no acompanhamento dos princípios científicos de um dado tema, haja vista uma revisão sistematizada poder ser restringida ao máximo em função de normas limitativas características de tal metodologia de revisão, ou seja, certos tópicos exigiriam uma conotação mais ampla, o que é peculiar à revisão narrativa. Não obstante, o rigorismo da sistematização pode ser útil na análise de determinadas questões (SILVA, 2019). Basicamente, os estudos de revisão bibliográfica poderão servir de fundamento seja quanto ao volume de informações, seja quanto à heterogeneidade de interpretações, ou ainda quanto à ausência de consenso acerca de um dado tema.

\section{CONSIDERAÇÕES FINAIS}

Observou-se que a Homeopatia está presente no cenário global há mais de dois séculos desde sua proposta por Samuel Hahnemann, cuja metodologia é compreendida como um sistema que entende o sujeito como um ser integral, não como partes isoladas. Como características essenciais, encontram-se a cura pelo semelhante, a medicação única, diluída e dinamizada, bem como a experimentação em pessoas sadias.

Avaliou-se que, mesmo sendo uma opção terapêutica, a homeopatia está baseada em definições muito pouco ortodoxas, desafiando a racionalidade. $\mathrm{O}$ modelo utiliza o princípio de cura pela semelhança, pelo uso de doses infinitesimais de drogas que, por terem sido experimentadas previamente em sujeitos sadios, proporcionam sinais similares em sujeitos doentes.

Investigou-se que, embora tenha experenciado altos e baixos, a credibilidade da Homeopatia aumentou substancialmente nas últimas décadas. Todavia, ainda se desconhece, em várias situações, o mecanismo de ação destas drogas, apesar de a terapia mostrar-se eficaz na clínica do paciente.

Averiguou-se que, resultado de uma concepção psicossomática e global da doença, a semiologia homeopática entende os diversos aspectos do afetado, em um diagnóstico individualizado. 
Aferiu-se que, no intuito de legitimar a terapia homeopática, é imprescindível a produção de estudos que possam confirmar os princípios homeopáticos, bem como ensaios clínicos para verificar e corroborar a efetividade no tratamento de patologias diversas.

Verificou-se que várias iniciativas têm possibilitado o ensino dos preceitos da homeopatia em instituições de ensino, introduzindo disciplinas na matriz curricular, e produzindo evidências científicas e práticas clínicas.

Constatou-se que a forma de compreender a saúde, a doença e as práticas de assistência não são únicas, devendo haver a opção terapêutica que possa ser adotada pela população e não apenas por parte desta.

Concluiu-se que a homeopatia nacional figura no cenário global, em função do desenvolvimento da prática, bem como por ter sido inserida na Política Nacional de Práticas Integrativas e Complementares, oferecida pelo Sistema Único de Saúde (SUS), embora ainda existam lacunas no atendimento, e na farmácia, que necessitam ser sanadas, de forma a, em futuro próximo, serem parte importante de um sistema abrangente de atenção à saúde.

Assim, em síntese, o presente estudo analisou as principais características da terapia homeopática. Sugere-se, ainda, que outros estudos sejam desenvolvidos para discutir e fortalecer o tema da presente pesquisa, levando-se em consideração a evolução da sociedade e dos achados farmacológicos, bem como os principais autores do campo da medicina e assistência à saúde.

\section{REFERÊNCIAS}

BORNMANN, Lutz; MUTZ, Rudiger. Growth rates of modern science: A bibliometric analysis based on the number of publications and cited references. Journal of the Association for Information Science and Technology, v. 66, n. II, p. 2215-2222, 2015. DOI: https://doi.org/Io.1002/asi.23329.

BRASIL. (2006). Ministério da Saúde. Política Nacional de Práticas Integrativas e Complementares no SUS - PNPIC-SUS. Secretaria de Atenção à Saúde, Departamento de Atenção Básica. Brasília, DF: Presidência da República, Ministério da Saúde, 2006. Disponível em:

http://bvsms.saude.gov.br/bvs/publicacoes/politica_nacional_praticas_integrativas_compl ementares_2ed.pdf. Acesso em: 22 set. 2021. 
BRASIL. (2007). Agência Nacional de Vigilância Sanitária. Resolução RDC Anvisa n 67 , de 08 de outubro de 2007. Dispõe sobre Boas Práticas de Manipulação de Preparações Magistrais e Oficinais para Uso Humano em farmácias. Brasília, DF: Presidência da República, Agência Nacional de Vigilância Sanitária (ANVISA). Disponível em: https://www2o.anvisa.gov.br/segurancadopaciente/index.php/legislacao/item/rdc-67-de8-de-outubro-de-2007. Acesso em: 22 set. 202I.

BRASIL. (2008). Agência Nacional de Vigilância Sanitária. Resolução RDC Anvisa nº 87, de 2i de novembro de 2008. Altera o Regulamento Técnico sobre Boas Práticas de Manipulação em Farmácias. Brasília, DF: Presidência da República, Agência Nacional de Vigilância Sanitária (ANVISA). Disponível em: http://bvsms.saude.gov.br/bvs/saudelegis/anvisa/2008/resoo87_21_II_2008.html. Acesso em: 22 set. 2021.

BRASIL. (20II). Farmacopeia Homeopática Brasileira. 3. ed. Brasília, DF: Presidência da República, Ministério da Saúde, 20II. Disponível em: http://portal.anvisa.gov.br/farmacopeia-homeopatica. Acesso em: 22 set. 202I.

BRASIL. (2014). Conselho Federal de Farmácia. Resolução n 601 , de 26 de setembro de 2014. Dispõe sobre as atribuições do farmacêutico no âmbito da homeopatia e dá outras providências. Diário Oficial da União, Brasília, DF, I3 out. 2014b. Seção I, p. 75I. Brasília, DF: Presidência da República, Conselho Federal de Farmácia (CFF), 2014. Disponível em: http://www.cff.org.br/userfiles/file/resolucoes/6or.pdf. Acesso em: 22 set. 202I.

BRASIL. (2018). Ministério da Saúde. Política nacional de práticas integrativas e complementares no SUS (PNPIC): atitude de ampliação de acesso. Secretaria de Atenção à Saúde. Departamento de Atenção Básica. 2. ed. Brasília, DF: Presidência da República, Ministério da Saúde, 2018. Disponível em: http://www.saude.gov.br/saude-de-a$z$ /praticas-integrativas-e-complementares. Acesso em: 22 set. 2021.

BRASIL. (2019). Conselho Regional de Farmácia do Estado de São Paulo. Departamento de Apoio Técnico e Educação Permanente. Comissão Assessora de Homeopatia. Homeopatia. 3. ed. São Paulo: Conselho Regional de Farmácia do Estado de São Paulo, 2019. Disponível em: http://portal.crfsp.org.br/images/cartilhas/homeopatia.pdf. Acesso em: 22 set. 2021.

DANTAS, F. O medicamento homeopático provoca efeitos adversos ou agravações medicamentos-dependentes? Revista de Homeopatia, v. 8o, n. 1/2, p. 174-182, 2017.

DANTAS, F.; RAMPES, H. Do homeopathic medicines provoke adverse effects? A systematic review. Br. Homeopath. J., v. 89, suppl. I, p. S35-8, 2000.

DENEZ, K. B. Percepções dos usuários da clínica pública ou privada sobre a homeopatia e acesso aos medicamentos homeopáticos. 2015. 220f. Dissertação (Mestrado em Assistência Farmacêutica). Universidade Federal de Santa Catarina. Florianópolis, 2015. 
DENZIN, Norman K.; LINCOLN, Yvonna S. Handbook of qualitative research. Thousand Oaks-CA: Sage Publications, 2000.

DIAS, A. F. Fundamentos da homeopatia: princípios da prática homeopática. Rio de Janeiro: Editora Cultura Médica, 20oı.

DINIZ, D. S. A Ciência das Doenças e a Arte de Curar: Trajetórias da Medicina Hipocrática. (Dissertação) Mestrado em Saúde Coletiva do Instituto de Medicina Social. Universidade Estadual do Rio de Janeiro, Rio de Janeiro, 2006.

DOLCE-FILHO, R. Hierarquização de sintomas para a prescrição homeopática segundo Kent. Revista de Homeopatia, v. 71, n. I-4, p. I-13, 2008.

FARMACOPEIA HOMEOPÁTICA BRASILEIRA. 3. ed. São Paulo: Andrey, 20 I.

FONTES, O. L.; CESAR, A. T.; CHAUD, M. V.; TEIXEIRA, M. Z.; KISCHI, M. A.; AMORIM, V. O. de. Farmácia homeopática: Teoria e prática. 4. ed. Barueri: Manole, 2012.

FURUTA, S. E.; WECKX, L. L. M.; FIGUEIREDO, C. R. Estudo clínico, duplo-cego, randomizado, em crianças com amigdalites recorrentes submetidas a tratamento homeopático. Revista de Homeopatia, v. 80, n. I/2, p. 164-173, 2017.

GIL, Antonio Carlos. Como elaborar projetos de pesquisa. 6. ed. São Paulo: Atlas, 2017. 192 p. ISBN-10: 8597012617. ISBN-13: 978-8597012613.

GRECK, A. P. B. S. A homeopatia nas estomatites virais infantis: preliminar para gênio epidêmico. 2016. 46f. Monografia (Especialização em Homeopatia) - Escola Bahiana de Medicina e Saúde Pública. Salvador, 2016.

HAHNEMANN S. Organon da arte de curar. 6. ed. Ribeirão Preto: Museu de Homeopatia Abrahão Brickmann, 1995 .

HOLANDINO, C. A. Homeopatia e os Modelos Experimentais para a Compreensão das Propriedades Físico-Químicas e Biológicas dos Sistemas Dinamizados. Revista de Homeopatia, v. 72, n. 3-4, p. 15-18, 2009.

LABONIA FILHO, W. Rajan Sankaran: A Sensação em Homeopatia. Revista de Homeopatia, v. 73, n. I/2, p. 81-84, 2010.

LASTA, J. P. Preparados Homeopáticos na Germinação de Sementes de Feijão (Phaseolus vulgaris) Submetidas ao Teste de Envelhecimento Acelerado. 20Io. Xxxf. Monografia (Graduação em Engenharia Agrônoma). Universidade Comunitária da Região de Chapecó (UNOCHAPECÓ), Santa Catarina, zoro. 
LIMA, L. F. De; AlVES, A. M. C. V.; ROCHA, R. M. P.; CELESTINO, J. J. de H.; BRUNO, J. B.; RODRIGUES, A. P. R.; FIGUEIREDO, J. R. de. A homeopatia como alternativa no tratamento de distúrbios reprodutivos. Ciência Animal, v. 22, n. 2, p. 25-43, 2012.

LMHI. Scientific framework of homeopathy. Evidence based homeopathy 2015. Revised edition after 69th LMHI Congress, July 2014 (Paris, France).

MAGALHÃES, J. C.; GARDIN N. E.; NAKAMURA M. U. Medicamentos antroposóficos e homeopáticos: semelhanças e diferenças. Arte Médica Ampliada, v. 38, n. 2, p. 67-75, abr./mai./jun. 2018.

MARCONI, Marina de Andrade; LAKATOS, Eva Maria. Metodologia do trabalho científico. 8. ed. São Paulo: Atlas, 2017. 256 p. ISBN-ıo 8597010665. ISBN-I3 978-8597010664.

MELNYK, Bernadette M.; FINEOUT-OVERHOLT, Ellen. Making the case for evidence-based practice. In: MELNIK, Bernadette M.; FINEOUT-OVERHOLT, Ellen. Evidence-based practice in nursing and healthcare. A guide to best practice. 4. ed. Filadélfia: Wolters Kluwer Health, 2018.

MINAYO, Maria Cecília S. O desafio do conhecimento: pesquisa qualitativa em saúde. São Paulo-SP: Hucitec, 2014. 416 p. ISBN-10: 8527101815. ISBN-13: 978-8527101813.

MONTEIRO, João Paulo. Novos estudos humanos. São Paulo: Discurso Editorial, 2003.

MOREIRA, Walter. Revisão de Literatura e Desenvolvimento Científico: conceitos e estratégias para confecção. Janus, Lorena, a. I, n. I, p. 2I-30, 2004.

PUSTIGLIONE, M.; GOLDENSTEIN, E.; CHENCINSKI, M. Homeopatia: um breve panorama desta especialidade médica. Revista de Homeopatia, v. 8o, n. I/2, p. I-17, 2017.

SANKARAN, R. (2010). A Sensação em Homeopatia. [S. 1.]: Organon, 2010.

SANKARAN, R. (2013). Sensação refinada. I. ed. [s/1]: Organon, 2013.

SANTOS, R.; SÁ, F. M. P. de. Homeopatia: histórico e fundamentos. Revista Científica da Faculdade de Educação e Meio Ambiente, v. 5, n. I, p. 60-78, jan-jun, 2014.

SCHOLTEN, J. Homeopatia e os elementos. [S. 1.]: Organon, 2013.

SILVA, Wesley Mendes da. Contribuições e Limitações de Revisões Narrativas e Revisões Sistemáticas na Área de Negócios. Revista da ANPAD, Maringá, v. 23, n. 2, p. III, marc./abr., 2019. DOI: http://doi.org/I0.1590/1982-7849rac2019190094.

SINSEN, J. Role of homeopathy in managing male and female infertility. European Journal of Integrative Medicine, v. 2, p. 217-265, 2010. 
SIQUEIRA, C. M. Alterações Celulares Induzidas por um novo Bioterápico do Tipo Nosódio Vivo sobre as Linhagens MDCK e J774. 2009. I64f. (Dissertação) Mestrado em Ciências Farmacêuticas. Universidade Federal do Rio de Janeiro, Rio de Janeiro, 2009.

SLOMP JUNIOR, H.; FEUERWERKER, L. C. M.; MERHY, E. E. Histórias de vida, homeopatia e educação permanente: construindo o cuidado compartilhado. Ciência \& Saúde Coletiva, v. 20, n. 6, p. 1795-1803, 2015.

SOUSA, Luís Manuel Mota de; FIRMINO, Cristiana Furtado; MARQUES-VIEIRA, Cristina Maria Alves; SEVERINO, Sandy Silva Pedro; PESTANA, Helena Castelão Figueira Carlos. Revisões da literatura científica: tipos, métodos e aplicações em enfermagem. Revista Portuguesa de Estudos Regionais, Angra do Heroísmo, v. I, n. I, jun. 2018.

TEIXEIRA, M. Z. (1998). A natureza imaterial do homem: estudo comparativo do vitalismo homeopático com as principais concepções médicas e filosóficas. São Paulo: Petrus, 1998.

TEIXEIRA, M. Z. (1999). Similitude in modern pharmacology. Br. Homeopath. J., v. 88, n. 3, p. II2-I20, I999.

TEIXEIRA, M. Z. (200o). O vitalismo hahnemanniano na prática clínica homeopática. Revista de Homeopatia APH, v. 65, n. 2, p. 23-34, 2000.

TEIXEIRA, M. Z. (2002). O Vitalismo Homeopático ao Longo da História da Medicina. Homeopat. Bras., v. 8, n. 2, p. 109-123, 2002.

TEIXEIRA, M. Z. (2007). NSAIDs, Myocardial infarction, rebound effect and similitude. Homeopathy, v. 96, n. I, p. 67-68, 2007.

TEIXEIRA, M. Z. (2009). Antidepressants, suicidality and rebound effect: evidence of similitude? Homeopathy, v. 98, n. I, p. II4-I2I, 2009.

TEIXEIRA, M. Z. (2010). Statins withdrawal, vascular complications, rebound effect and similitude. Homeopathy, v. 99, n. 4, p. 255-262, 2010.

TEIXEIRA, M. Z. (20II). Evidências Científicas da Episteme Homeopática. Revista de Homeopatia, v. 74, n. I-2, p. 33-56, 201 .

TEIXEIRA, M. Z. (2013). A natureza imaterial do homem: estudo comparativo do vitalismo homeopático com as principais concepções médicas e filosóficas. 2. ed. São Paulo: Marcus Zulian Teixeira, 2013. Disponível em:

https://www.homeozulian.med.br/livros/A\%20Natureza\%2oImaterial\%20do\%20Homem \%20-\%20Dr.\%2oMarcus\%2oZulian\%2oTeixeira.pdf. Acesso em: 22 set. 202I. 
TEIXEIRA, M. Z. (2014). Estudos homeopáticos: 20 anos de publicações na Revista de Homeopatia da Associação Paulista de Homeopatia. Revista de Homeopatia, v. 77, n. 1/2, p. $28-44,2014$.

TEIXEIRA, M. Z.; CARNEIRO, S. M. T. P. G. Efeito de ultradiluições homeopáticas em plantas: revisão da literatura. Revista de Homeopatia, v. 8o, n. I/2, p. II3-132, 2017.

VANDERLEI, C. E. D. A. Homeopatia numa Perspectiva Sistêmica: Contribuições da Saúde para o Desenvolvimento Local Sustentável. 2010. 137f. (Dissertação) Mestrado Profissional em Gestão do Desenvolvimento Local Sustentável. Faculdade de Ciências da Administração de Pernambuco, Recife, 20ı. Disponível em:

http://www.cesaho.com.br/biblioteca_virtual/arquivos/arquivo_446_cesaho.pdf. Acesso em: 22 set. 2021.

WAISSE, S. Pesquisa clínica em homeopatia: revisões sistemáticas e ensaios clínicos randomizados controlados. Revista de Homeopatia, v. 8o, n. I/2, p. 133-147, 2017. 